\title{
Why Monorail Systems Provide a Great Solution for Metropolitan Areas
}

\author{
Peter E. Timan
}

Received: 5 January 2015/Revised: 3 February 2015/Accepted: 6 February 2015/Published online: 4 April 2015

(C) The Author(s) 2015

\begin{abstract}
Faced with the escalating demand for public transportation in metropolitan areas, transportation authorities are challenged to select a technology that will satisfy the often conflicting demands of high capacity and reliable service, urban fit, minimized environmental impact and budget restrictions. There are many technologies available today that can provide medium to high capacity mass transit service, however, in many cases these technologies are costly or are not suited to today's urban environment. High capacity has typically implied costly underground tunneling or obtrusive elevated metro systems that required extensive infrastructure disruption. Although monorail systems have been around for some time, only recent developments such as Bombardier's INNOVIA Monorail 300 System have permitted transit authorities to now consider monorail as a mainstream contender to meet their mass transit requirements.
\end{abstract}

Keywords Elevated - Automated D Driverless - Transit . Monorail · System

\section{Introduction}

Monorail systems today must enhance city development by exploiting monorail's iconic aesthetics and easy urban integration allowing cost-effective and fast turnkey construction in both greenfield and brownfield mass transit applications.

\section{P. E. Timan $(\bowtie)$}

Bombardier Transportation, Kingston, ON, Canada

e-mail: peter.timan@ca.transport.bombardier.com

Editor: Xihe He
Fully automated operation is an essential ingredient allowing mass transit operators to provide the required frequent, reliable, safe and fast service demanded. Today's automatic train operation technologies must provide reliable short headways that maximize system capacity and permit optimized operations and maintenance regimes.

Today's monorail systems must respect the environment by providing low visual impact of both the guideway and vehicle while offering zero emissions. Notably, Bombardier's INNOVIA Monorail 300 solution uses advanced technologies including permanent magnet motors and lightweight construction to provide substantial energy savings resulting in operating cost savings as well as reduced $\mathrm{CO}_{2}$ emissions.

Monorail systems today must employ international mass transit standards in all aspects of vehicle and system design to provide durable and safe operations. As with any elevated transit system, monorail systems are no exception, requiring emergency walkway to provide assured means of evacuation.

Bombardier's new INNOVIA Monorail 300 System enables these key attributes of today's urban mass transit applications.

\section{Brief History of Monorails}

Early concepts for monorail systems as an alternative to conventional rail began surfacing in the 19th century. However, attempts to develop this technology into a commercial stage did not find success until well into the next century.

Historically, two types of monorail systems emerged from the early stages of development:

- The suspension railway systems on which the vehicle hangs under the fixed track-originally designed as freight transportation. The earliest urban application 


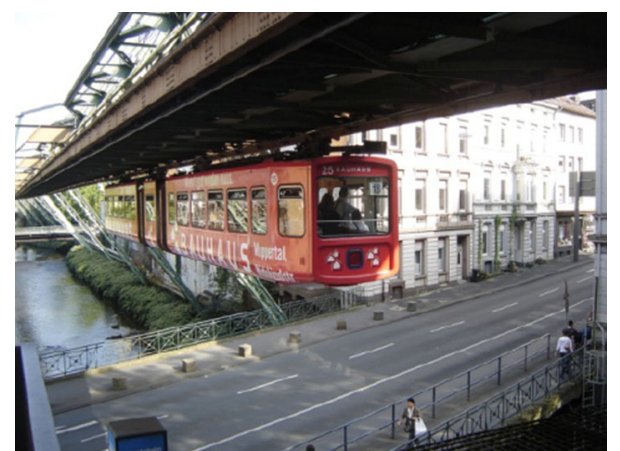

Fig. 1 Schwebebahn Wuppertal, Germany in operation since 1901

was the Wuppertal Monorail (Fig. 1) that was installed in 1901 and is still in use today.

- The straddle-beam monorail system uses a vehicle that straddles a reinforced beam. In the 1950s, a German company by the name of ALWEG pioneered this technology, and installed its first system at Walt Disneyland in California (Fig. 2). Most successful wheeled monorails today can trace their roots to the straddle beam ALWEG type monorail technology including the extensive Chongqing Monorail as well as Hitachi, Scomi and Bombardier Monorail.

\section{Bombardier's History in Monorail Systems}

Embarking in a new chapter of turnkey solutions, Bombardier installed its first complete automated INNOVIA Monorail 100 System in 1991 in Tampa, Florida; followed by the JTA Skyway Monorail system in 1998 in Jacksonville, Florida (Fig. 3). This was the beginning of extensive development of the technology, further supported by the acquisition of Adtranz, (owners of Von Roll Monorail technology), and a license agreement with Disney.

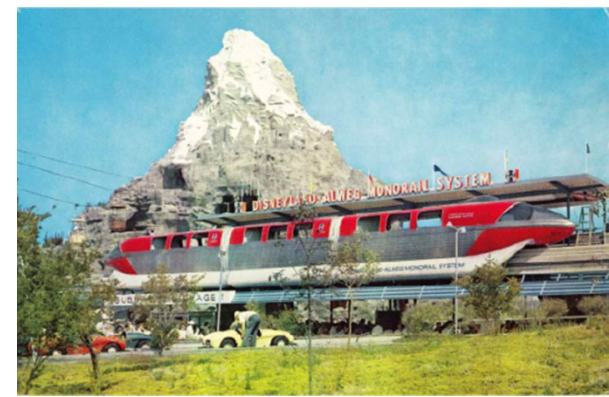

Fig. 2 First ALWEG monorail in commercial operation-Disneyland 1959

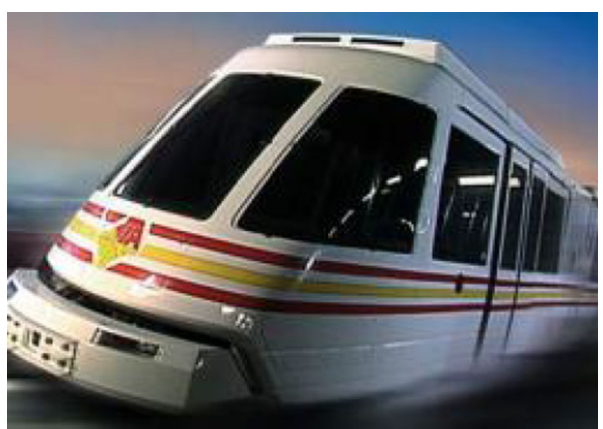

Fig. 3 INNOVIA Monorail 100_Jacksonville (1998)

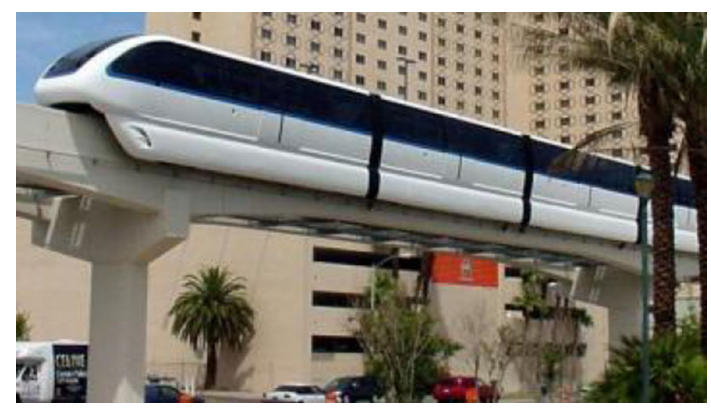

Fig. 4 INNOVIA Monorail 200-Las Vegas (2004)

In 2004, Bombardier launched its second-generation monorail technology in Las Vegas, Nevada (Fig. 4). This new INNOVIA Monorail 200 System technology featured many aesthetic and operational improvements including design and testing to mass transit industry standards.

Leveraging the experience gained from earlier monorail projects and from other Bombardier installed automated mass transit systems around the world; Bombardier has now developed a new generation of its monorail, the INNOVIA Monorail 300 System (Fig. 5). The INNOVIA Monorail 300 System provides a truly robust mass transit solution for today's urban mobility challenges.

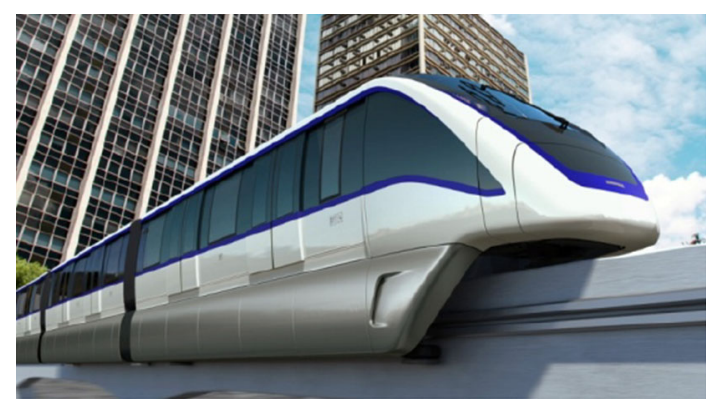

Fig. 5 INNOVIA Monorail 300—Sao Paulo and KAFD 


\section{Today's Urban Mobility Challenges}

Public planning authorities often face conflicting demands to provide reliable and accessible high capacity public transportation. In the past, city planners have provided this kind of service by specifying metro systems. However, installing metro systems are typically very costly and often involved extensive relocation and destruction of valuable existing infrastructure. In some cases, metro systems are not an option due to existing infrastructure, which results in no high capacity transit system at all.

Congested city streets result in inefficient flow of goods, services and people with the result that commerce is restricted and productivity declines (Fig. 6). Expanding existing streets is often not an option due to already intense development and the severe limitation of available land. In any case, adding traffic lanes to already congested streets only results in added pollution and noise with costly health and social implications (Fig. 7).

Many cities around the world today have well-established infrastructure such as water, hydro and electric services that have been developed and expanded over time making tunneling or surface transportation solutions very costly. In addition, many older cities have valuable or culturally sensitive historical buildings that are often in the path of preferred public transportation routes. Transit systems must accommodate steep grades and sharp curves to avoid destruction of valuable infrastructure and to minimize land acquisition and expropriation.

Elevated transit systems avoid the need for costly tunneling and minimize the need to relocate existing utilities; however, elevated metro systems typically require wide visually obtrusive deck construction and often still require extensive destruction of existing infrastructure.

Mass transit systems must be able to attract people away from existing inefficient modes of transport, providing not only reliable high capacity transportation, but also visually

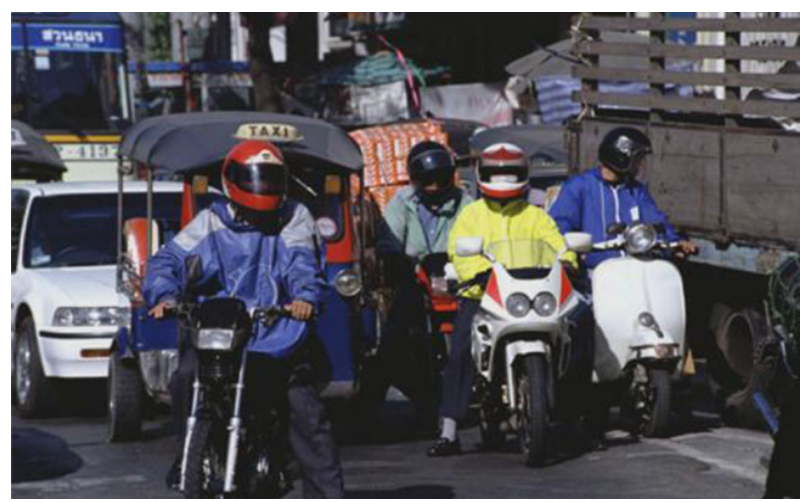

Fig. 6 Congestion limits commerce

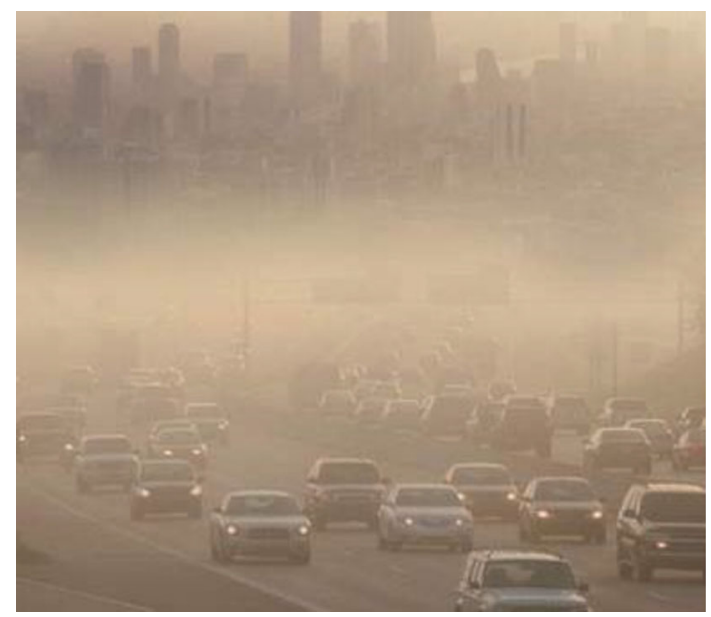

Fig. 7 Pollution results in costly health and social implications

enhancing the community. The key to attracting ridership is the need to provide a transit system with efficient and reliable service through fully automated driverless operation, which not only provides enhanced reliability but also operational flexibility, reduced energy consumption and increased passenger safety. As with any elevated mass transit system, passenger safety must be a key consideration through specified mass transit industry safety standards including specification of emergency evacuation walkway along the entire elevated guideway.

Although monorail systems have been around for many years, only recent developments such as Bombardier's INNOVIA Monorail 300 System have permitted transit authorities to now consider monorail as a mainstream contender to meet their mass transit requirements.

\section{New Generation Monorail for Metropolitan Areas- Market Requirements}

A need for new mass transit system technologies that meets market requirements and cost less within a reduced timeframe prompted the development of Bombardier's new INNOVIA Monorail 300. Market studies clearly indicated a need in the medium to high capacity range from 2000 to 20,000 pphpd (passengers per hour per direction) and up to 40,000 pphpd (Figs. 8, 9).

The market studies also concluded that key to market acceptance of any new development was the need to ensure that mass transit industry standards must form the basis for any new technology as well as stringent safety standards and features.

Key requirements for market penetration include the need for the transit system to provide what could be termed "delighter" features, which would attract increased 


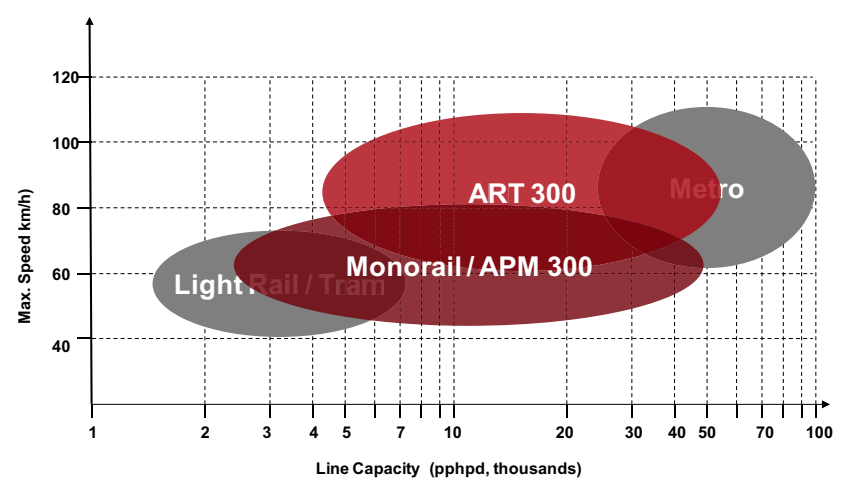

Fig. 8 Typical market segments

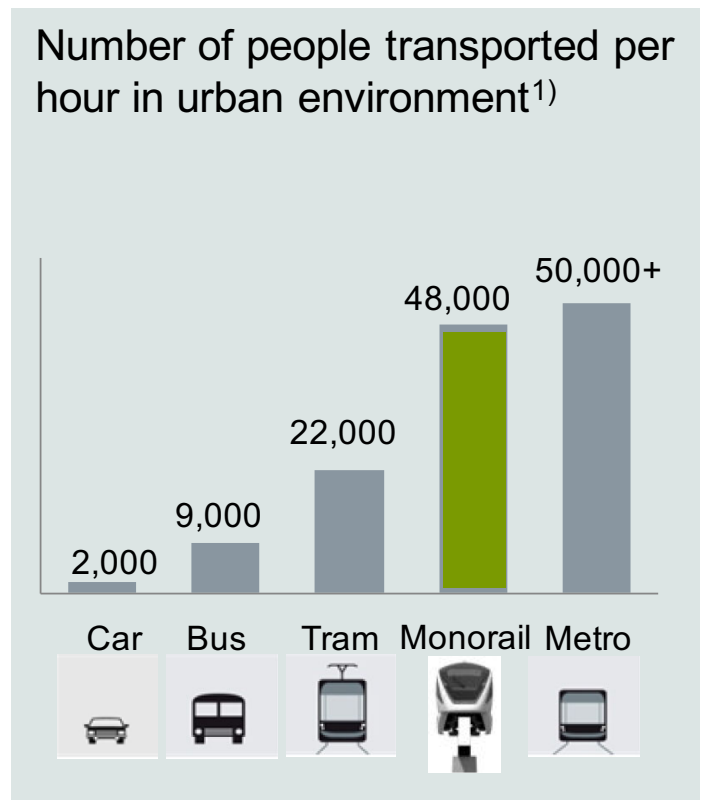

Fig. 9 Transport capacity. Number of people crossing a 3-5 m-wide space in an hour in an urban environment. Source International Association of Public Transport (UITP) - Monorail data added by Bombardier

ridership away from existing congested, foot print intensive, polluting automotive modes of transport. The kinds of delighter features that are proven to be effective in other mass transit applications are frequent, efficient and reliable service implemented through fully automated driverless operation. Other delighter features required in modern transportation systems today include attractive aesthetics, energy efficient, non-polluting, quiet and comfortable operation that blend well into existing communities.

Optimization of a monorail system to best fulfill the market requirements can only be done when considering all elements of the transit system over the complete system life cycle from guideway and power distribution systems to the vehicle and operations \& maintenance (Fig. 10).
Bombardier Transportation has taken this whole system approach to optimize the new INNOVIA Monorail 300 system design resulting in an optimized medium to high capacity mass transit system for today's congested urban environments.

Historically monorail developments have focused on specific single elements of the mass transit system such as the vehicle resulting in reduced overall competitiveness and failing to meet many market requirements. From a public transport authority perspective, the best way to achieve an optimized monorail transit system is to use a full system Turnkey procurement process ideally including a significant operations and maintenance element of at least 10-15 years. Turnkey system procurement allows the best tradeoff between vehicle and wayside elements such as guideway and station construction [1]. When a significant operations and maintenance component is also included as part of the initial contract, then total life cycle and maintenance costs are automatically included in the design optimization thus resulting in the lowest overall life cycle cost of the system. By placing the full system under one consortium there are clear lines of responsibility since critical system integration tasks are the responsibility of the single consortium entity thus ensuring that the transit authority obtains the contracted system performance (Fig. 11).

The full system turnkey procurement process places responsibility for all system elements under one roof thus minimizing transit authority risk while at the same time providing the transit authority with the lowest fixed price and avoiding scope and budget creep. A pre-qualification process may be beneficial to ensure that only qualified and proven suppliers can prepare submissions.

\section{Bombardier's INNOVIA Monorail 300 System- Answering The Market}

Bombardier considered all aspects of the system in the development of its INNOVIA Monorail 300 System. As discussed above, key to low cost and minimized disruption of existing infrastructure was the need to optimize for primarily elevated alignments, which then became the key driving force behind many of the design decisions. The BOMBARDIER INNOVIA Monorail 300 System is particularly suited for connector distributor and line haul type systems with line capacities in the range of 2000-20,000 pphpd and readily expandable to 48,000 pphpd.

\section{Driverless Automated Operation}

By taking a full system approach to the design of the INNOVIA Monorail 300, it was clear that fully 
Fig. 10 Full system integration is critical to success

\section{Key Transit System Elements - Turnkey System Procurement}

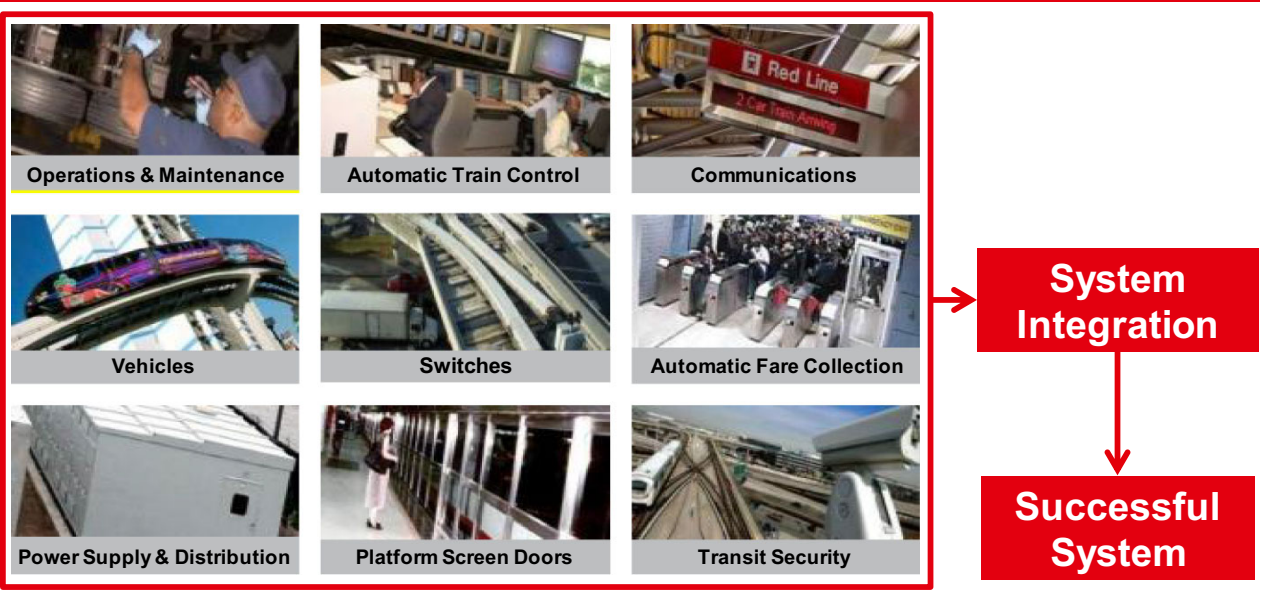

Fig. 11 A procurement structure with full turnkey system responsibility under a single entity provides best opportunity for project success

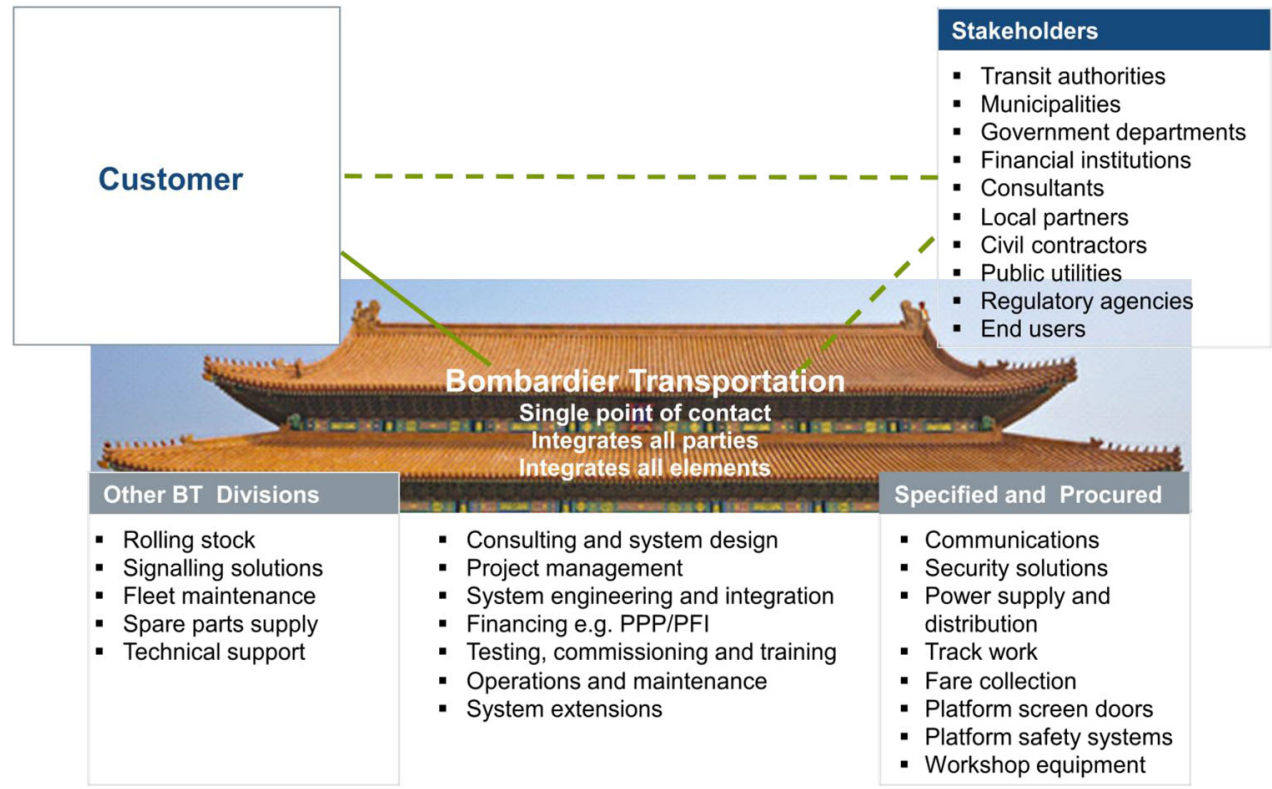

Bombardier is the leader in driverless transit systems around the world with over 40 driverless systems installed since 1971 (Fig. 13).

Ridership studies have shown that increasing train frequency has very significant impact on attracting new riders on a transit system. In retrospect, this would seem obvious since the key element for a passenger is to reach his final destination reliably and in the shortest possible time. A rider would typically start his journey on a bus of feeder system, transfer to a line haul system and then perhaps transfer to a second feeder system at the end of his route. As train intervals are increased, the rider must account for this by leaving earlier for his journey to the point that riders will choose other less desirable forms of transportation as the total trip time increases. Studies have shown that train 
Future Growth

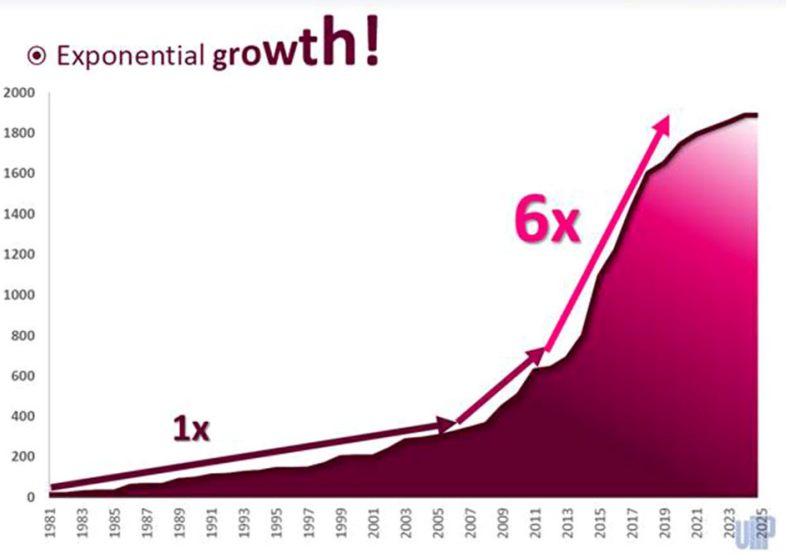

Fig. 12 Rapid growth projected for automated driverless systems [2]

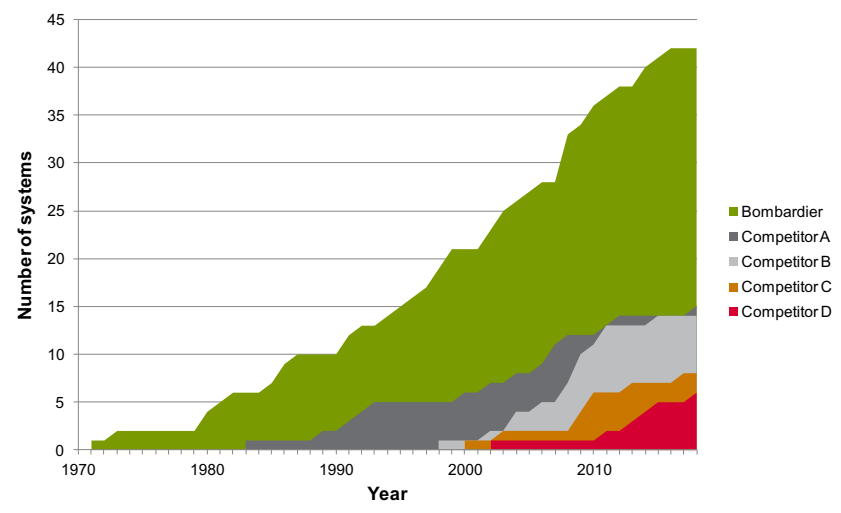

Fig. 13 Bombardier a leader in driverless systems

frequency with headways less 2 min between trains can significantly increase ridership.

The benefits of fully automated driverless operation go beyond increased ridership having significant cost advantages to the overall system. The ATC system is capable of very short headways, which permits the shortest possible trains (Fig. 14) to provide the required system service capacity. Shorter, more frequent trains permit much shorter station platforms, which in turn result in reduced need for land expropriation, reduced land acquisition cost, reduced station cost and reduced quantity of other system elements such as station communications equipment, platform screen doors, maintenance workshop, etc. Manually

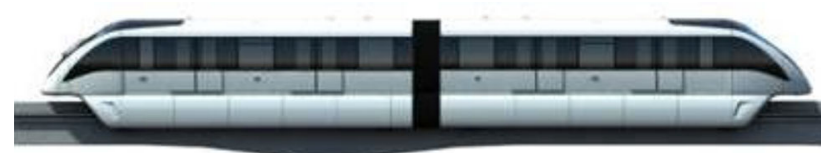

Fig. 14 Frequent short trains result in increased ridership operated ATP protected systems today are typically limited to headways greater than $120 \mathrm{~s}$ or more and are often not able to reliably sustain even these headways over extended periods. Automated driverless systems on the other hand are proven to sustain reliable headway performance as low as $60 \mathrm{~s}$ depending on train length and system configuration although most common minimum headways range from 75 to $90 \mathrm{~s}$ for most automated systems.

Fully automated driverless operation results in reliable increased average train speed since acceleration rate, braking rate and dwell times can be consistently maintained independent of any particular driver. Increased average train speed can significantly reduce required fleet size thus reducing system capital cost and maintenance costs (Fig. 15).

Automated operation provides the added benefit of reduced energy consumption by employing consistent acceleration, cruising and braking parameters optimized for the particular alignment and train technology.

\section{Elevated Guideway}

Bombardier Monorail guideways comprise slender beams that provide flexibility in alignment and ease of construction with minimum visual impact.

Designed to integrate seamlessly into different environments, including through buildings and structures, INNOVIA Monorail 300 System infrastructure requires minimal land expropriation and meets the most stringent urban transit, environmental and safety standards. The system technology permits slender contemporary guidebeams, which both guide the vehicle and provide its structural support.

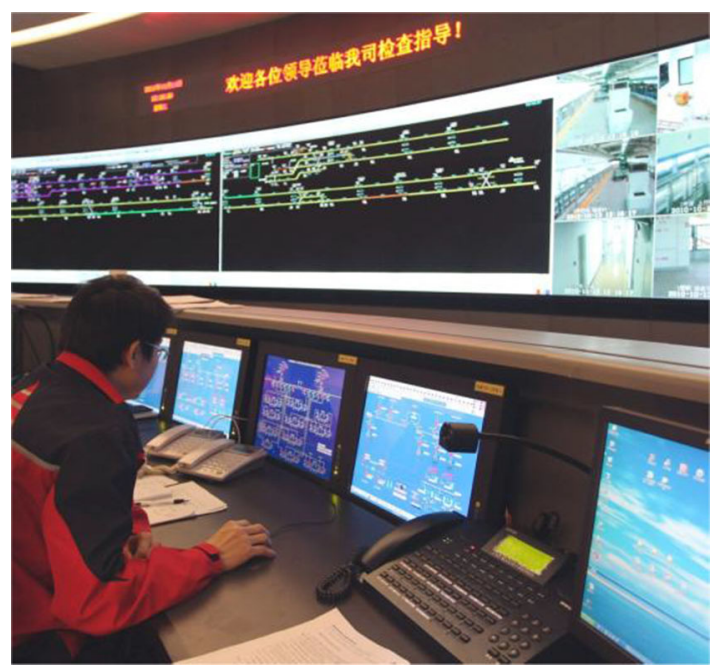

Fig. 15 Automated operation key to optimized performance 
Today's fast-paced urban environment creates a high demand for quick implementation of efficient transportation systems. Disruption to everyday city life is simply not an option. Time is short to transform a city's transportation network, and the INNOVIA Monorail 300 System permits cost-effective, rapid installation in comparison to other mass transit technologies.

Bombardier developed its INNOVIA Monorail 300 System to minimize the costs and disruption of civil construction. The pre-cast, post-tensioned elevated guideway structure is constructed off-site to allow for exceptionally rapid assembly on site (Figs. 16, 17, 18, 19). In addition, the elevated guideways avoid the need for potentially expensive and time-consuming tunneling works, a major advantage when introducing a new transit system in existing dense urban areas.

Bombardier's focus for designing minimized guidebeam size was to optimize civil construction cost. This was primarily accomplished by minimizing the train loading applied to the beam. This led to an important requirement for the vehicle design to minimize weight and center of gravity as well as to minimize the overall vehicle silhouette thus significantly reducing static and dynamic loading as well as wind loading on the guidebeam structure.

The lowest vehicle weight in its class and narrowest guidebeam width requirement of $690 \mathrm{~mm}$, contribute to these cost savings by maximizing pier spacing and reducing substructure requirements.

\section{Urban Fit}

Transit systems must be able to accommodate steep grades and sharp curves to fit the existing conditions of congested urban environments. The BOMBARDIER INNOVIA Monorail 300 System can accommodate grades of up to $6 \%$ and curve radii of 46-m radius permitting the guideway alignment to optimally follow existing rights of way (Fig. 20).

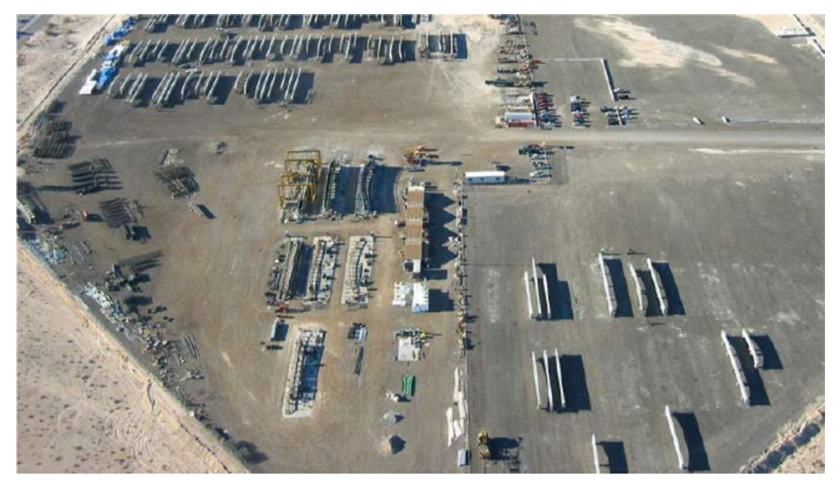

Fig. 16 Construction yard

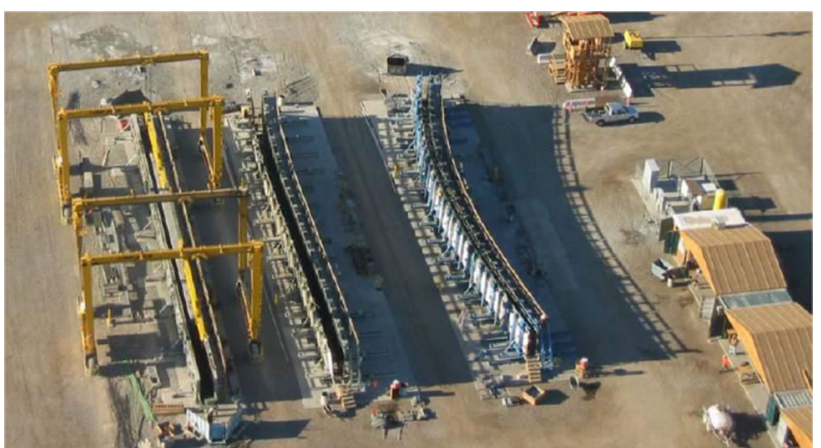

Fig. 17 Beam casting

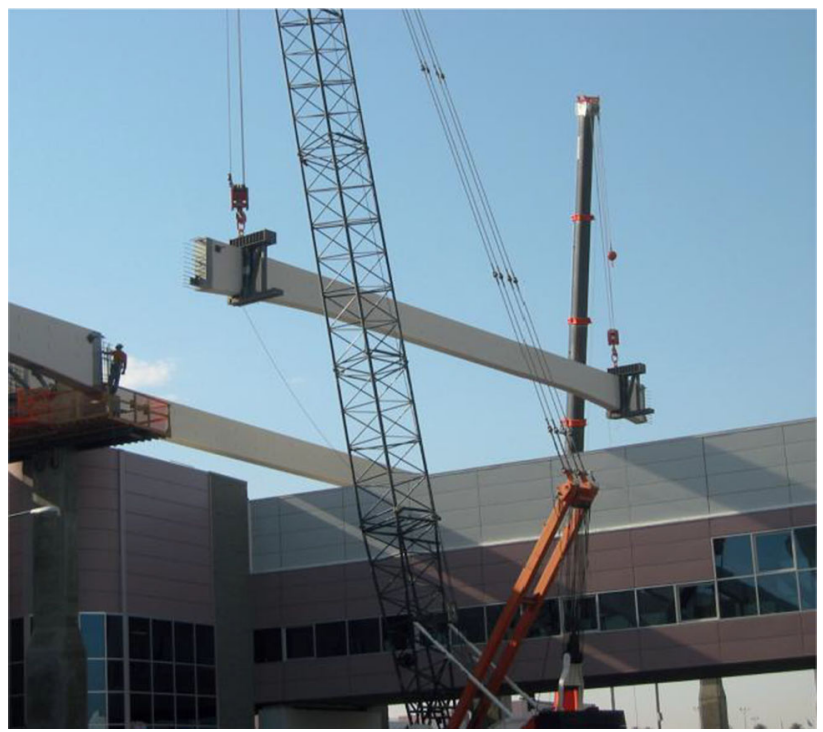

Fig. 18 Spanning existing infrastructure

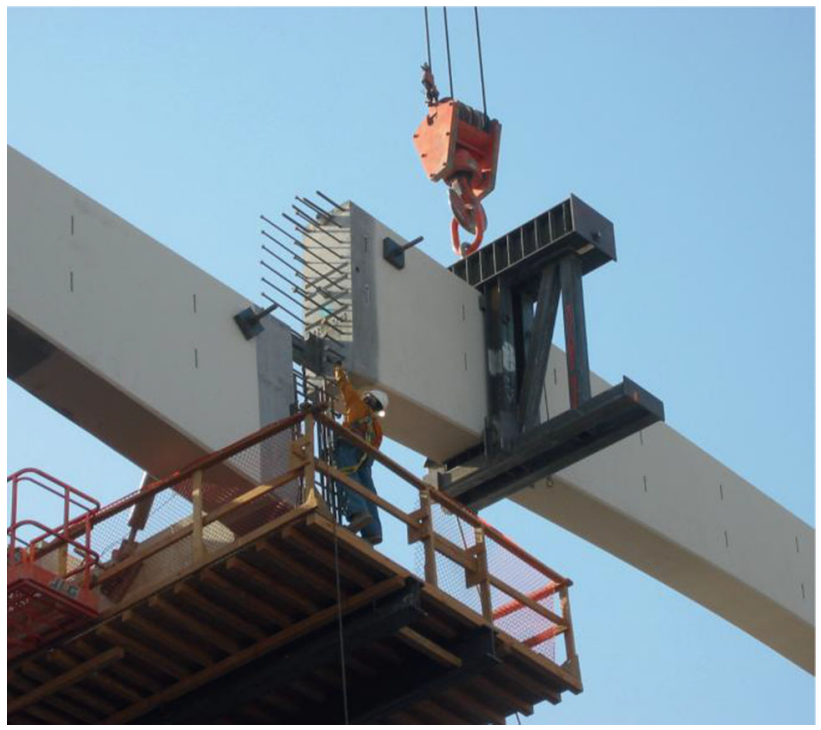

Fig. 19 Beam placement 


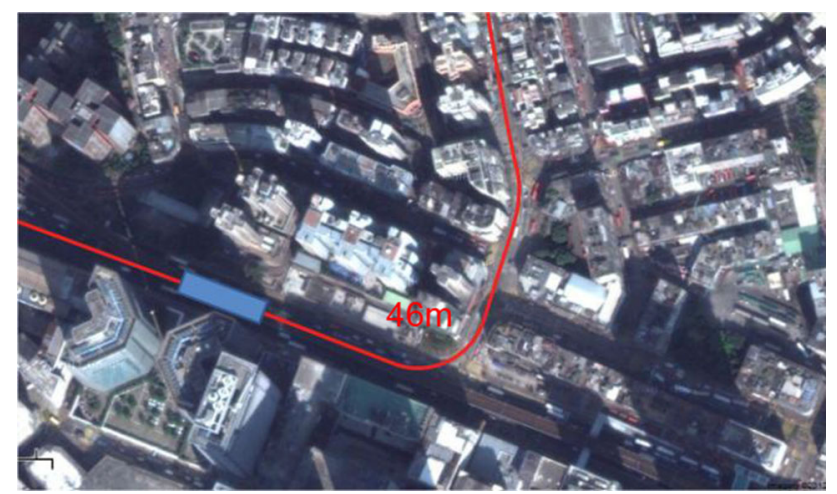

Fig. 20 Minimize costs by following existing rights of way

The ability to follow existing rights of way such as existing roadways results in minimized land intake which reduces the need for divisive property expropriation as well as reducing the need to destroy existing valuable or culturally sensitive buildings. The long span capability of the multi-span posted tensioned beam design minimizes the need to relocate existing utilities such as water, sewer, communications and hydro.

A key requirement for good urban fit includes unobtrusive stations, which is accomplished by implementing short headways between trains thus permitting shorter and less obtrusive stations.

Good urban fit requires improved conditions for people and city living (Fig. 21). The social aspects of mass transit cannot be overlooked, as they are critical to market acceptance and successful transit system implementation. Bombardier paid special attention to the social implications of mass transit by designing the INNOVIA Monorail 300 System to be an attractive and efficient public transit system. It can be installed close to existing homes and businesses with low visual impact. The Bombardier INNOVIA Monorail 300 uses low noise metro style rubber tires as well as direct drive permanent magnet hub motors

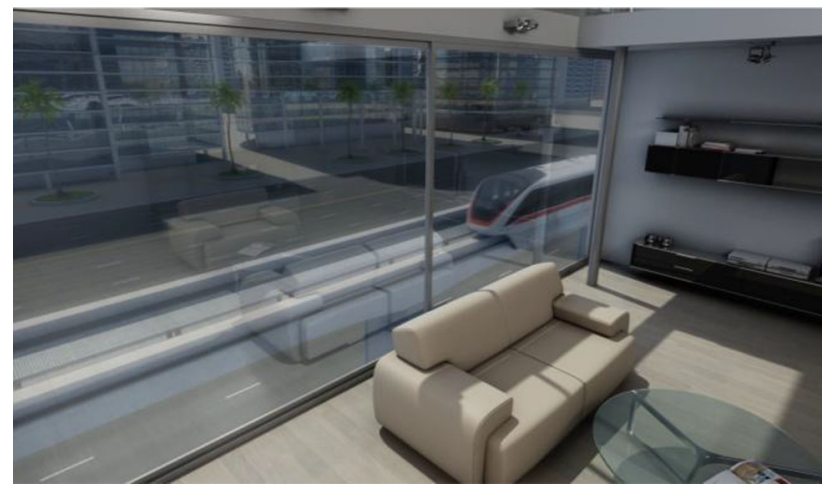

Fig. 21 Quite operation and iconic aesthetics enhance city living conditions minimizing noise and vibration. The INNOVIA Monorail 300 has zero emissions helping to improve air quality in congested city landscapes.

\section{Safety}

In addition, using driverless operation and design to mass transit industry standards, other key safety requirements for a mass transit system include the recommended use of platform screen doors. Platform screen doors not only prevent inadvertent falls from the platform edge, but also avoid typical rider induced service interruptions as well as providing the capability to have climate controlled station platforms (Fig. 22).

Platform screen doors fully enclose the platform edge, and are synchronized to open and close with the vehicle doors to allow access and egress to and from the vehicle. It is in fact the consistent stopping accuracy provided by the automatic driverless train control, which allows for the safety benefits of platform doors. Emergency access doors, included in the panels between the automatic doors, allow additional access in case of emergency or failure.

As with any elevated transit system, a safe means of evacuation is required to be available at any point along the alignment. Existing standards such as NFPA 130 recommend the use of an emergency walkway or equally safe means of evacuation; it must also demonstrate a safe evacuate the entire fully loaded train within 15 min. Many independent studies show that the only reliable fail-safe means of evacuation that is able to meet this requirement is an emergency walkway along the entire alignment. All other means of evacuation fail to achieve the required evacuation time in all locations or in all anticipated conditions of failure or hazard.

Emergency walkways should be part of initial contract to ensure aesthetic integration into the guideway design (Fig. 23). Emergency walkways can be implemented in a visually aesthetic way and are cost-effective since they

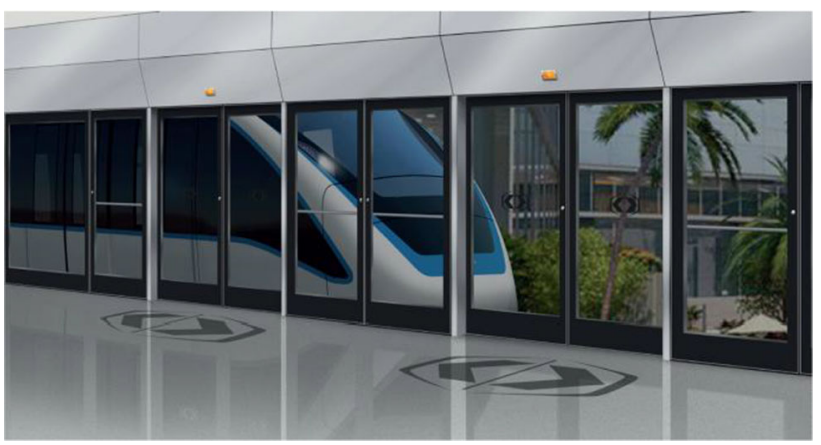

Fig. 22 Platform doors enhance passenger safety 


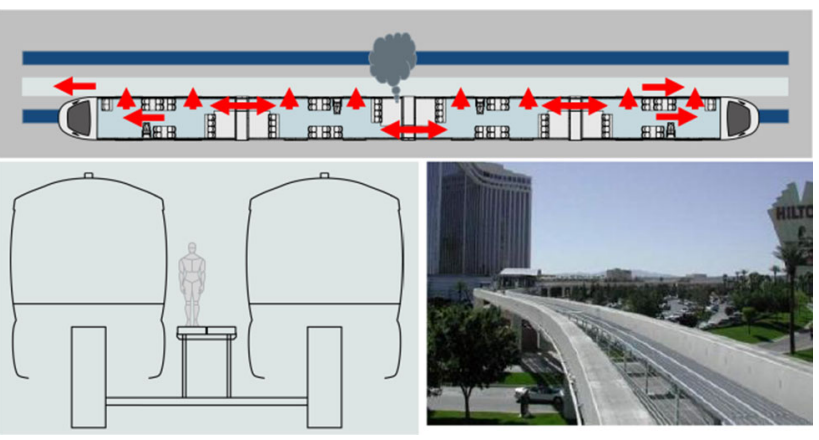

Fig. 23 Emergency walkway permits safe and fast evacuation

provide multiple additional functions of improved maintenance access to guideway elements as well as providing a natural support for the transit system power and communication cables (Fig. 24).

Including requirements for an emergency walkway in the initial contract helps avoid contractual disputes with costly budget overruns and compromise solutions that either are marginally effective (walkway not easily accessible from the vehicle) or visually intrusive.

\section{Switching}

INNOVIA Monorail 300 switches are either beam replacement or multi-position pivot switches. The beam replacement switches are used on the mainline and multiposition pivot switches are used in storage yard areas. In both cases, they are structural steel assemblies incorporating steel guideway beams that pivot to provide guidance and support, routing the train from one lane to another. Power rails are continuous throughout the switches to maintain vehicle propulsion.

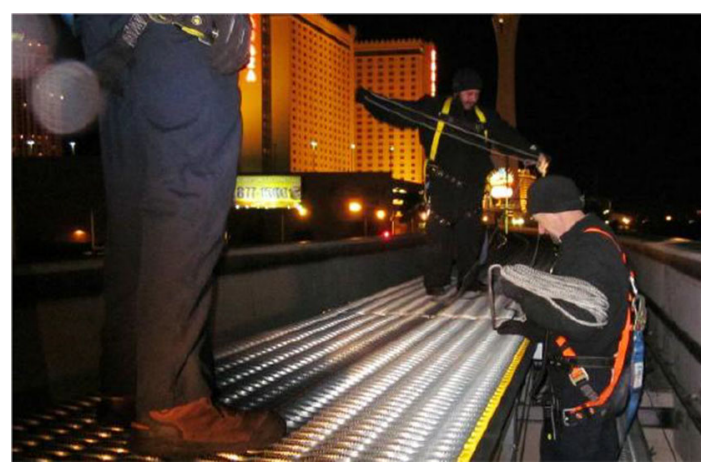

Fig. 24 Emergency walkway provides guideway maintenance access

\subsection{Beam Replacement Turnouts}

The beam replacement switch consists of beams with tangent and spiral sections pinned at one end and supported on carriages at the other to permit rotation of the beams (Figs. 25, 26). These switches permit operation at line speed in tangent direction while spiral geometry in the turnout direction allows maximum curve speed while enhancing ride comfort. Beam replacement switches are used in various configurations to provide single or double crossovers.

\subsection{Pivot Switches}

The pivot switch is a low speed switch with a tangent steel beam that pivots at one end and capable of rotating into up to four positions is used to provide access into storage and maintenance lanes (Fig. 27).

\section{Bombardier's INNOVIA Monorail 300-Vehicle Development and Key Features}

Bombardier's INNOVIA Monorail 300 is designed to comply with stringent international mass transit standards and architecture typically associated with light metro rail technologies. The use of these standards and architecture provides a robust vehicle built on proven metro subsystem technologies providing the operator with reliable performance and 30-year design life (Fig. 28).

The INNOVIA Monorail 300 System vehicle allows total flexibility of car configuration in up to 8-car trains and with a newly designed gangway, riders can freely move between cars and enjoy improved visual aesthetics.

INNOVIA Monorail 300 System vehicles operate from transit standard $750 \mathrm{Vdc}$ power supply distribution system.

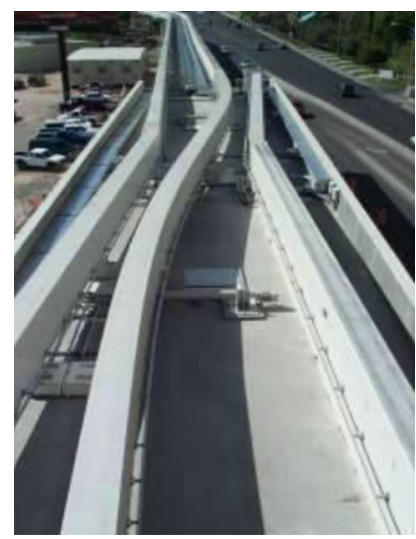

Fig. 25 Turnout position 


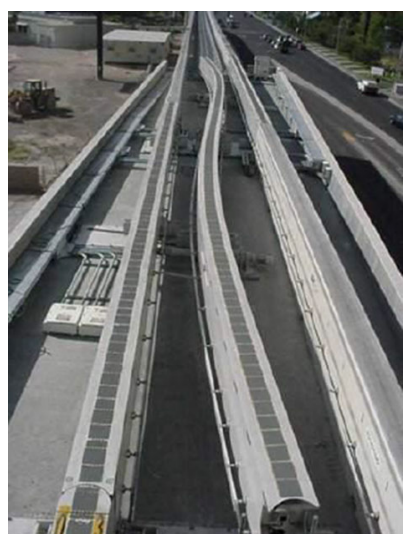

Fig. 26 Tangent position

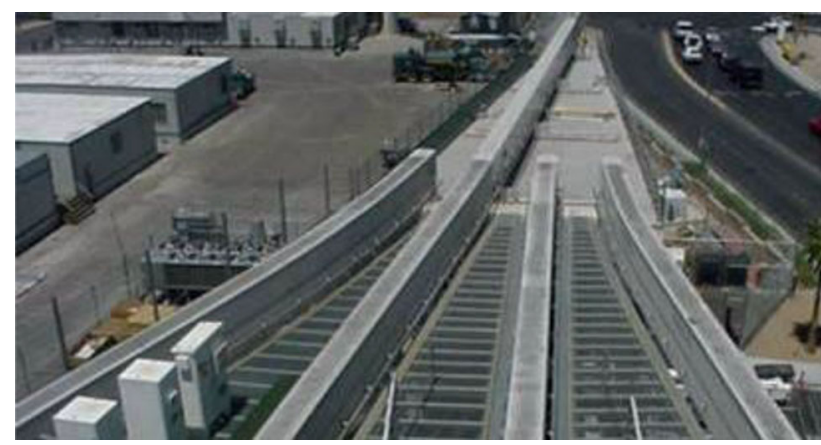

Fig. 27 Multi-position pivot switch

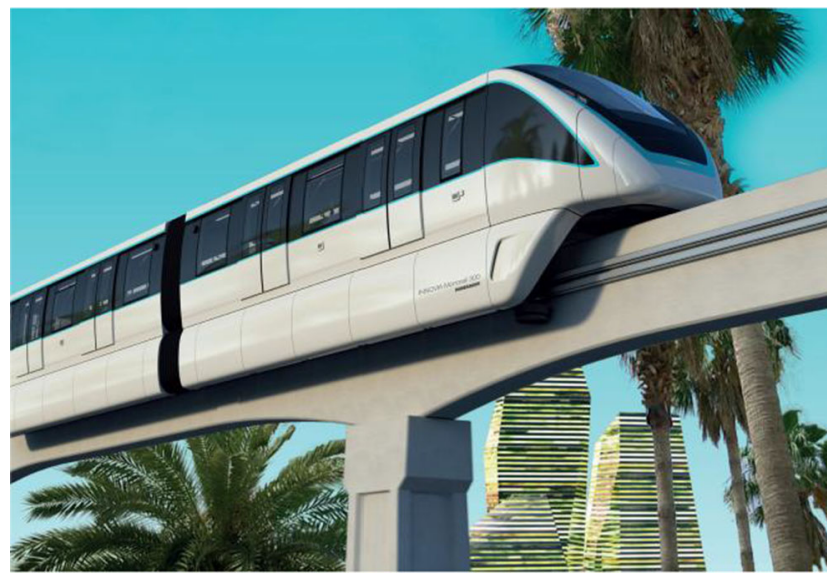

Fig. 28 Bombardier's INNOVIA Monorail 300 System

The INNOVIA Monorail 300 System features a sleek and modern vehicle equipped with energy efficient technologies. The combination of lightweight carshell design and other advanced system technologies results in substantial energy savings compared to other monorail and metro technologies. Bombardier designed its monorail vehicles to combine futuristic aesthetics in conjunction with open visual vehicle interior, large side and end windows and independent bogie suspension to provide passengers with a superior ride experience.

A key development for the INNOVIA Monorail 300 vehicle is the single axle dual tired bogie with permanent magnet hub motor propulsion. This development was critical for achieving both the low floor, low profile aesthetic vehicle while simultaneously providing access for intercar walkthrough capability. The combination of single axle bogie and low floor configuration permitted the low profile vehicle with the lowest weight per standard passenger capacity in the industry.

The single axle bogie configuration provides significant performance advantages due to perfect radial alignment of each axle at all times regardless of travel direction or curve condition (Fig. 29). This configuration results in further reduced vehicle weight, reduced rolling resistance as well as reduced tire wear in curves compared to other dual axle bogie configurations.

Creating a comfortable and impressive interior is an important part of drawing passengers to any transportation system. Elegantly designed, the passenger compartments allow flexible seating arrangements to meet a variety of system capacities.

When designing the INNOVIA Monorail 300 System vehicles, Bombardier made incorporating an inter-car gangway a top priority. These vehicle gangways greatly increase capacity, but also increase the passenger's sense of safety and security (Fig. 30). The freedom to walk between cars is an appealing feature and contributes to the spacious and open feel of the vehicle.

Large side and front windows add to the feeling of spaciousness while allowing for natural light and a scenic view (Figs. 31, 32). The passenger-friendly interiors are

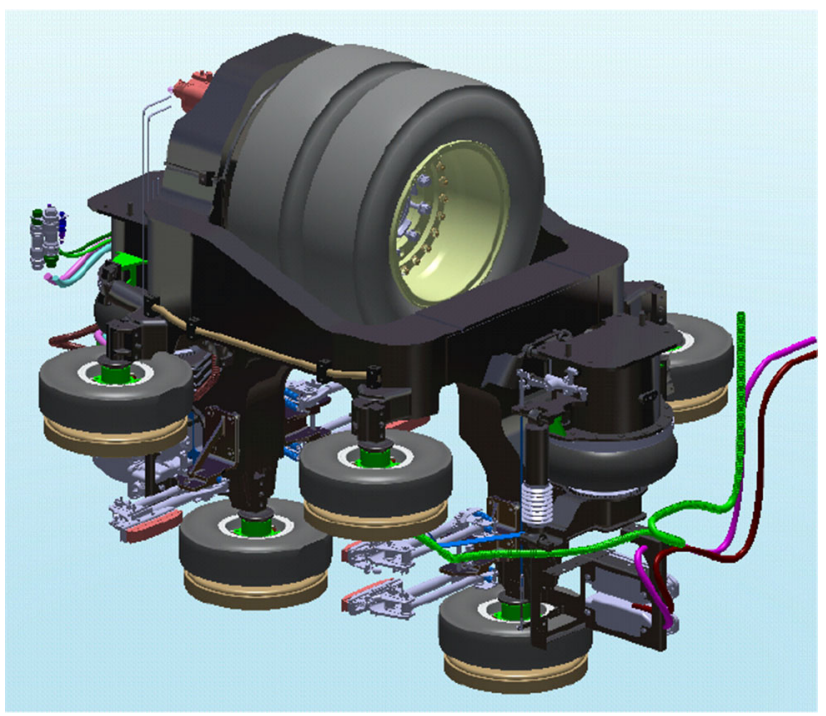

Fig. 29 Single axle bogie radially aligned in curves 


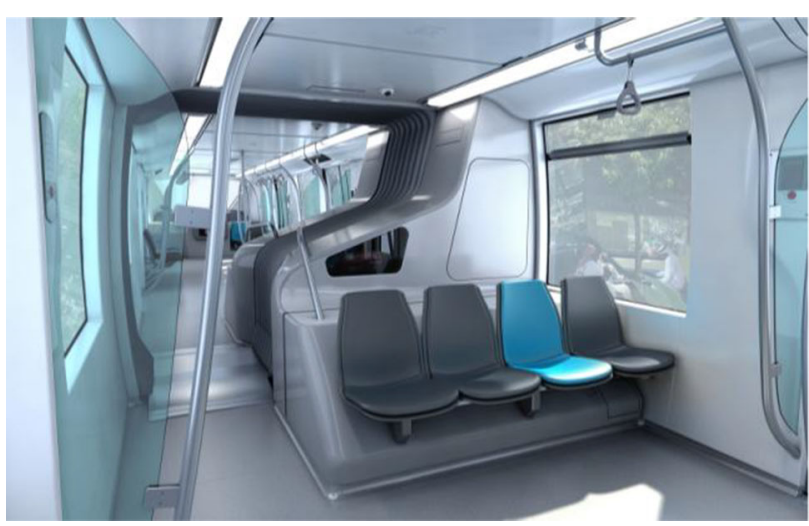

Fig. 30 Gangway permits free passage between cars

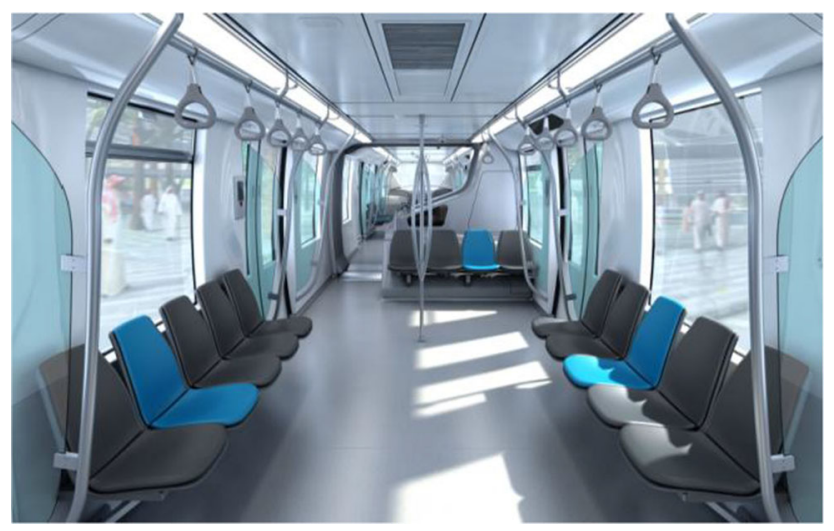

Fig. 31 Spacious interior ease passenger flow

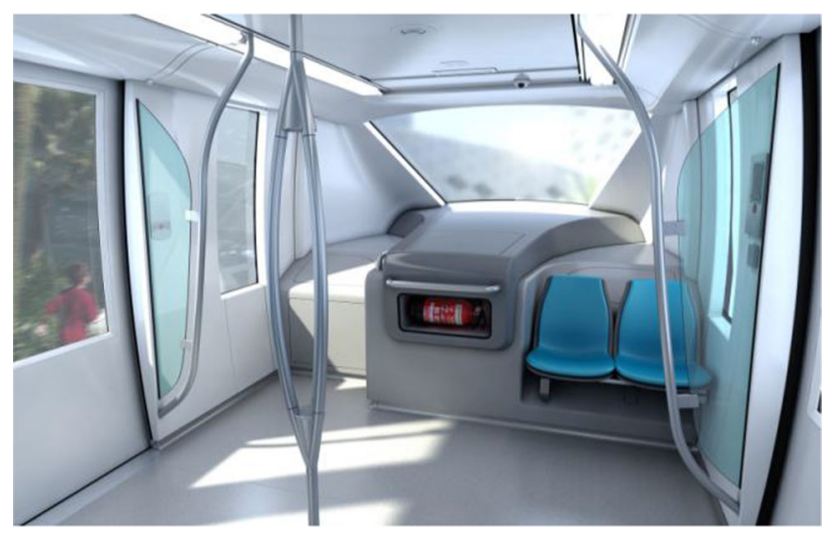

Fig. 32 Large windows contribute to passenger-friendly experience

accessible for passengers in wheelchairs, with strollers/ prams or even bicycles. These customizable interiors can be equipped with bike or luggage racks.

Large side doors permit fast egress and ingress of passengers at stations thus minimizing required station dwell time and reducing the trip time for the passenger as well as minimizing fleet size for the operator.
Vehicles are outfitted with an advanced information system for station details or emergency evacuation instructions, thus passengers will receive clear and timely instructions. Modern LCD display screens can be included in each vehicle as an additional option for general information or advertising.

The INNOVIA Monorail 300 System vehicles have low noise through the effective carshell insulation design, low aggression metro rubber tires, low vibration direct drive hub motor drive and micro-plug side doors, effectively creating a quiet and enjoyable trip.

In accordance with ASCE 21 Automated People Mover Standard [3], the maximum operational load of the INNOVIA Monorail 300 System end car is 16-seated passengers and 105 standees at 6 passengers $/ \mathrm{m}^{2}$. The operational load of the INNOVIA Monorail 300 System vehicle middle car is $16-18$ seated plus $115-117$ standees at 6 passengers $/ \mathrm{m}^{2}$.

Engineered for increased efficiency and capacity, these attractive and low profile vehicles allow for flexible arrangement. The standard vehicle configuration permits two, four, six and eight car trains; however, three, five and seven car trains are also an option, if best suited to project requirements.

The maximum operating speed of the INNOVIA Monorail 300 is $80 \mathrm{~km} / \mathrm{h}$ which when combined with reliable high acceleration and braking capability result in high average train speed.

\section{Design for the Environment}

Design for the environment is a major focus of the INNOVIA Monorail 300 vehicle. Bombardier's focus on the environment is seen in all aspects of the system design including minimized consumption of material, minimized consumption of energy, minimized rolling resistance and wear, minimized noise, low visual intrusion system elements and maximized use of recyclable materials.

Material consumption to construct the system guideway and stations is much smaller than similar capacity elevated metro systems and has been designed to be the best in the industry for mass transit monorail applications.

Energy consumption is minimized through best in the industry lightweight vehicle construction, as well as use of energy efficient technologies; such as permanent magnet hub motors, LED lighting, sealed microplug doors, vehicle thermal insulation, low drag coefficient vehicle design, automated operation to optimize train performance. Short frequent trains increase power distribution system receptivity during electric braking regeneration, and permit short stations to minimize lighting and environmental control energy consumption. Intelligent power management 
shedding of non-essential loads when the vehicle is placed into sleep mode reduces energy consumption.

The environmental benefits of the single axle bogie include reduced energy consumption due to reduced rolling resistance as well as reduced tire dust pollution due to reduced tire wear.

Other aspects of environmental consideration include Bombardier's industry leading position to ensure stringent elimination of prohibited materials.

\section{Operations and Maintenance}

INNOVIA Monorail 300 Systems includes the capability to provide full life cycle operations and maintenance services, which is a core part of Bombardier's Systems division product offering. Bombardier is a leading operator and maintainer of many automated transit systems around the world.

Direct operation and maintenance involvement, and vast transit system experience enables Bombardier to provide system availability guarantees and to provide optimized system and vehicle maintenance regimes (Fig. 33).

Passenger and employee safety, world-class customer service, high system and equipment reliability and overall cost effectiveness are central to Bombardier's approach to operations and maintenance.

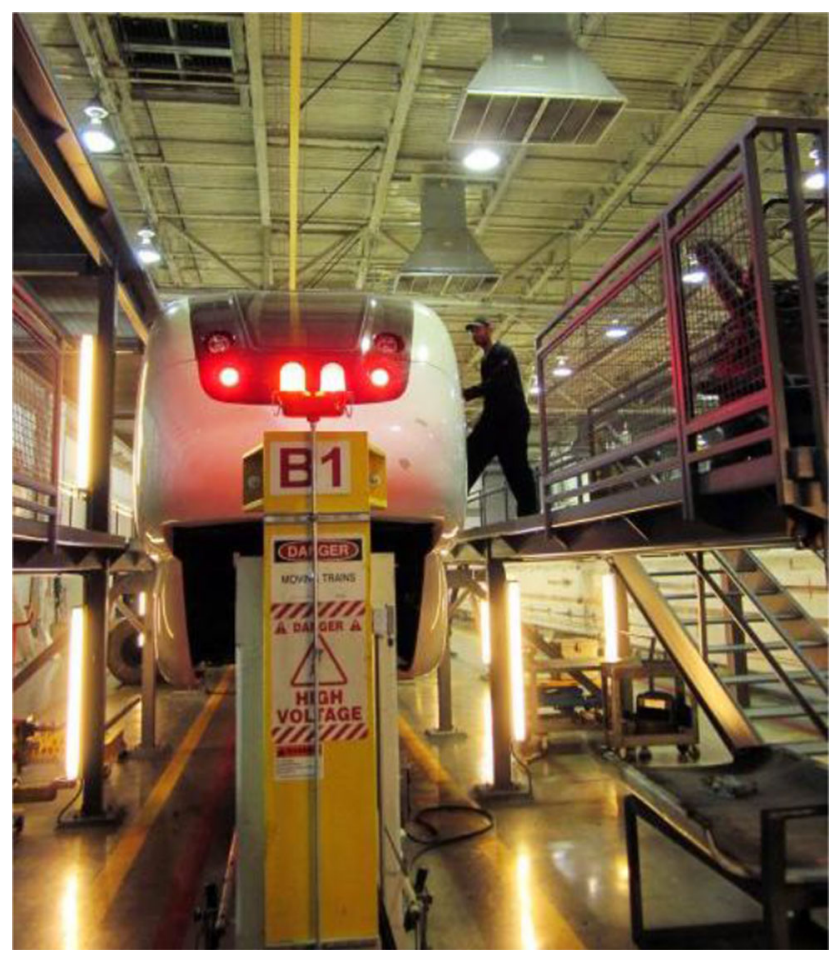

Fig. 33 Fleet maintenance services in Las Vegas
Key to success has been Bombardier's move toward predictive maintenance to optimize operation and maintenance regimes (Fig. 34). This approach is based on collection of key performance data, which is analyzed for data trending and visualization in order to provide advanced predictive maintenance and to permit rapid fault identification and resolution.

The benefits of this focus on predictive maintenance include increased system availability by minimizing the occurrence of service affecting failures through tracking of trends and early mitigation.

Other benefits include improved customer service by extending the system's operating life and extending equipment life through optimal performance of maintenance.

The net benefit to the transit authority is reduced total cost of ownership through extended maintenance intervals, potential elimination of historically identified frequent tasks, automated vehicle inspections, reduced planned maintenance activities and reduced spares holdings.

\section{Conclusion}

Monorail technology is a very attractive transit technology. Its futuristic look and appeal is a big attraction for riders.

Recent developments such as Bombardier's INNOVIA Monorail 300 System have opened opportunities for new applications of medium to high capacity mass transit monorail systems. The benefits of urban fit, light and unobtrusive civil structure, high grade and small curve capabilities, fast project implementation, etc., can be fully leveraged by transit authorities to address transit challenges. To ensure reliable, efficient high capacity service, transit authorities must specify mass transit industry standards for both system and vehicle elements.

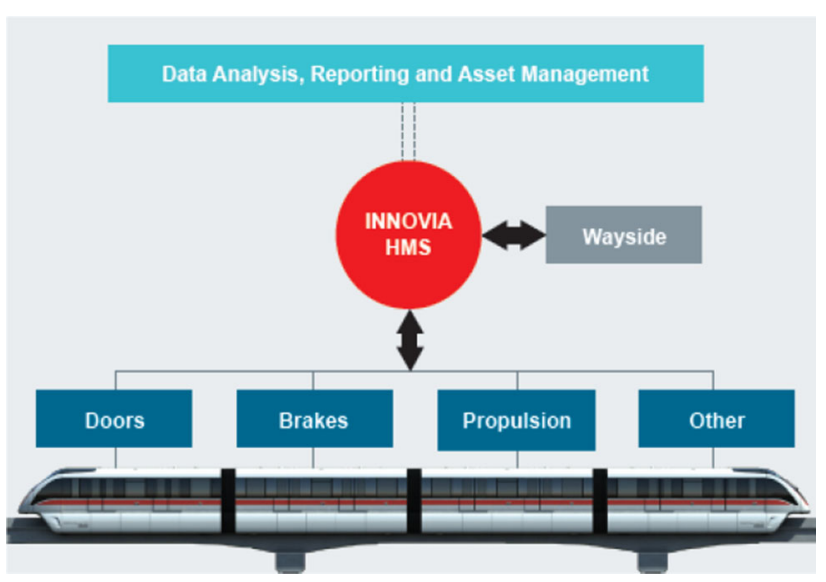

Fig. 34 Predictive maintenance optimizes system performance 
Transit authorities now have the opportunity to pursue monorail systems for mass transit applications, which were not previously considered viable alternatives to heavy metro technology when existing infrastructure and high tunnel cost were an issue.

To obtain best overall monorail system cost and performance, transit authorities should use a full turnkey procurement approach or similar based on clearly defined performance parameters and preferably including a significant period of operations and maintenance to capture full life cycle costs. In this way, the transit authority will be able to evaluate submissions with the true full picture in terms of overall system life cycle cost. A pre-qualification process may be beneficial to ensure that only qualified and proven suppliers are permitted to prepare submissions.

\section{References}

1. Didrikson PV (2008) Specification and procurement of fully automated transit systems. Presented at rail solutions asia conference, Kuala Lumpur, 12 June 2008

2. Malla R (2013) UITP observatory of automated metros: the trend to automation. Presented at 4th automated metro seminar, London, 6 Sept 2013

3. ANSI/ASCE/T\&DI 21-13 (2013) Automated people mover standards. American Society of Civil Engineers
Peter E. Timan was born in 1956 in Kingston, Canada. He received a B. Sc in Applied Science, Mechanical Engineering from Queen's University, Canada in 1979. He has been employed by Bombardier Transportation since 1980 and is presently a Senior Expert in Mass Transit and Monorail Systems. He held the position of Monorail System Product Manager for eight years culminating in the development of the Bombardier INNOVIA Monorail 300 Mass Transit Product. His current interests are focused in the area of research and development related to Monorail and Metro LIM systems. He is an executive member of the International Monorail Association (IMA) and he has presented at many IMA conferences worldwide since 2010. He has also presented a paper at the Chongquin International Monorail Conference in 2013 where he was presented with an "Outstanding Expert Award". 